\title{
Monitoring the influx of new species through citizen science: The first introduced ant in Denmark
}

\author{
Julie K Sheard ${ }^{\text {Corresp., } 1}$, Nathan J Sanders ${ }^{2}$, Carsten Gundlach $^{3}$, Sämi Schär ${ }^{4}$, Rasmus S Larsen ${ }^{5}$ \\ ${ }^{1}$ Center for Macroecology, Evolution and Climate, Globe Institute, University of Copenhagen, Copenhagen, Denmark \\ 2 Environmental Program, Rubenstein School of Environment and Natural Resources, University of Vermont, Burlington, Vermont, United States \\ 3 Department of Physics, Technical University of Denmark, Kgs. Lyngby, Denmark \\ 4 Unaffiliated, Dietikon, Switzerland \\ 5 Section for Ecology and Evolution, Department of Biology, University of Copenhagen, Copenhagen, Denmark \\ Corresponding Author: Julie K Sheard \\ Email address: julie.sheard@sund.ku.dk
}

Climate change and invasive species threaten biodiversity, yet rigorous monitoring of their impact can be costly. Citizen science is increasingly used as a tool for monitoring exotic species, because citizens are geographically and temporally dispersed, whereas scientists tend to cluster in museums and at universities. Here we report on the establishment of the first exotic ant taxon (Tetramorium immigrans) in Denmark, which was discovered by children participating in The Ant Hunt. The Ant Hunt is a citizen science project for children that we ran in 2017 and 2018, with a pilot study in 2015. Tetramorium immigrans was discovered in the Botanical Garden of the Natural History Museum of Denmark in 2015 and confirmed as established in 2018. This finding extends the northern range boundary of $T$. immigrans by almost $460 \mathrm{~km}$. Using climatic niche modelling, we compared the climatic niche of $T$. immigrans in Europe with that of $T$. caespitum based on confirmed observations from 2006-2019. Tetramorium immigrans and T. caespitum had a $13 \%$ niche overlap, with $T$. immigrans showing stronger occurrence in warmer and drier areas compared to $T$. caespitum. Mapping the environmental niches onto geographic space identified several, currently uninhabited, areas as climatically suitable for the establishment of $T$. immigrans. Tetramorium immigrans was sampled almost three times as often in areas with artificial surfaces compared to $T$. caespitum, suggesting that $T$. immigrans may not be native to all of Europe and is being accidentally introduced by humans. Overall, citizen scientists collected data on ants closer to cities and harbours than scientists did, and had a stronger bias towards areas of human disturbance. This increased sampling effort in areas of likely introduction of exotic species naturally increases the likelihood of discovering species sooner, making citizen science an excellent tool for exotic species monitoring, as long as trained scientists are involved in the identification process. 


\section{Monitoring the influx of new species through citizen}

2 science: The first introduced ant in Denmark

3

4 Julie K. Sheard ${ }^{1 *}$, Nathan J. Sanders ${ }^{2}$, Carsten Gundlach ${ }^{3}$, Sämi Schär ${ }^{4}$, Rasmus Stenbak Larsen ${ }^{5}$

5

$6 \quad{ }^{1}$ Center for Macroecology, Evolution and Climate, Globe Institute, University of Copenhagen,

7 Denmark

8 2Environmental Program, Rubenstein School of Environment and Natural Resources, University

9 of Vermont, Burlington, Vermont, USA

$10{ }^{3}$ Technical University of Denmark, Department of Physics, Fysikvej, Building 309, 2800 Kgs.

11 Lyngby, Denmark

$12 \quad{ }^{4}$ Dietikon, Switzerland

13 5ection for Ecology and Evolution, Department of Biology, University of Copenhagen,

14 Denmark

$15{ }^{*}$ Corresponding author:

16 Julie Koch Sheard

17 Universitetsparken 15, 2100 København Ø, Denmark

18 Email address: Julie.sheard@sund.ku.dk 
19 Abstract

20 Climate change and invasive species threaten biodiversity, yet rigorous monitoring of their

21 impact can be costly. Citizen science is increasingly used as a tool for monitoring exotic species, 22 because citizens are geographically and temporally dispersed, whereas scientists tend to cluster

23 in museums and at universities. Here we report on the establishment of the first exotic ant taxon

24 (Tetramorium immigrans) in Denmark, which was discovered by children participating in The

25 Ant Hunt. The Ant Hunt is a citizen science project for children that we ran in 2017 and 2018, 26 with a pilot study in 2015. Tetramorium immigrans was discovered in the Botanical Garden of

27 the Natural History Museum of Denmark in 2015 and confirmed as established in 2018. This

28 finding extends the northern range boundary of $T$. immigrans by almost $460 \mathrm{~km}$. Using climatic

29 niche modelling, we compared the climatic niche of $T$. immigrans in Europe with that of $T$.

30 caespitum based on confirmed observations from 2006-2019. Tetramorium immigrans and $T$.

31 caespitum had a $13 \%$ niche overlap, with $T$. immigrans showing stronger occurrence in warmer

32 and drier areas compared to T. caespitum. Mapping the environmental niches onto geographic

33 space identified several, currently uninhabited, areas as climatically suitable for the

34 establishment of T. immigrans. Tetramorium immigrans was sampled almost three times as often

35 in areas with artificial surfaces compared to T. caespitum, suggesting that $T$. immigrans may not

36 be native to all of Europe and is being accidentally introduced by humans. Overall, citizen

37 scientists collected data on ants closer to cities and harbours than scientists did, and had a

38 stronger bias towards areas of human disturbance. This increased sampling effort in areas of

39 likely introduction of exotic species naturally increases the likelihood of discovering species

40 sooner, making citizen science an excellent tool for exotic species monitoring, as long as trained

41 scientists are involved in the identification process. 


\section{Introduction}

43 The introduction and establishment of new species outside of their native range, which then go

44 on to become invasive, threaten biodiversity (IPBES, 2019). Monitoring introduced and invasive

45 species (species that have been introduced to an area outside of their range by humans and as

46 invasives have a detrimental impact on nature, economy or human health) has been challenging

47 in general, but has become increasingly problematic and important with accelerating trade,

48 commerce (Meurisse et al., 2019) and climate change (Bellard et al., 2013). Recently, citizen

49 science is being called on as a potential tool for successfully monitoring biodiversity on a large

50 scale (Tulloch et al., 2013; Theobald et al., 2015; Sauer et al., 2017). Citizen science can help to

51 document introduced species in general, but particularly in some of the habitats typically missed

52 by traditional surveys.

53 Cities and harbours are both hotspots of introduction. In cities, conditions are typically

54 warmer due to the urban heat island effect (Oke, 1973) and are ideal starting points for the spread

55 of new species (von der Lippe \& Kowarik, 2007). Likewise, harbours are a major introduction

56 pathway (O’Connor \& Weston, 2010), especially of ants (Suarez et al., 2010). Yet studies of ant

57 communities in urban ecosystems are rare (but see Lessard \& Buddle, 2005; Toennisson et al.,

58 2011). In Denmark, 80 \% of foreign trade goes through Danish industrial harbours (Danske

59 Havne, 2017). Among other products, these ships carry agricultural products, fodder and

60 fertilisers through which new species can be introduced. While general surveys in cities and

61 harbours can be difficult, these are some of the habitats most available to citizen scientists.

62 Social insects, including ants, are among the most damaging invaders (Holway et al.,

63 2002). Over 150 ant species have been introduced outside their native range and five are listed

64 on the world's 100 most invasive species list by the Invasive Species Specialist Group (ISSG)

65 (Lowe et al., 2000; Sanders \& Suarez, 2011). Invasions by non-native ants has been shown to be

66 destructive to ecosystems and financially costly to humans (Holway et al., 2002; Del Toro et al.,

67 2012). Although Denmark currently has no established and widespread invasive ants, thirty non-

68 native species have so far been recorded (Schär et al., 2017), most of them in hothouses in cities.

69 In 2017 and 2018, with a pilot study in 2015, children, in schools or with their families,

70 collected ants for a project called the Ant Hunt (In Danish, "Myrejagten") at 792 sites Denmark.

71 Although not the main aim of the project, we predicted that due to the expected amount of

72 sampling in urban areas, new species for Denmark were likely to be discovered.

$73 \quad$ Here we report on the discovery of a newly established ant taxon for Denmark through

74 the citizen science project "the Ant Hunt", Tetramorium immigrans (Santschi, 1927).

75 Tetramorium immigrans has recently been raised to the level of a cryptic sister species of the

76 morphologically similar $T$. caespitum (Wagner et al., 2017). An even more recent study has

77 demonstrated that T. immigrans and T. caespitum hybridize (Cordonnier et al., 2019), making

78 identification difficult.

79 Tetramorium caespitum and T. immigrans are both palearctic species (Wagner et al.,

80 2017). However, while T. caespitum is common across all of Europe (Seifert, 2007), T.

Peer) reviewing PDF | (2019:10:42328:2:1:NEW 25 Feb 2020) 
81 immigrans is primarily found in the Mediterranean, Western Europe, Central Europe, the

82 Balkans, Eastern Europe, Anatolia and Caucasus (Wagner et al., 2017), is more thermophilic and 83 has a more southern and urban distribution than T. caespitum (Seifert, 2018; Wagner et al.,

84 2017). Using climatic niche modelling, we compare the climatic niche and habitat use in Europe 85 for these two taxa, in order to determine potential differences in their ecological preferences.

86 Finally, we compare the distance to cities and harbours along with sampled habitat types for data 87 collected through the Ant Hunt with data collected by scientists from 1990-2015 to determine the 88 extent to which data collection by citizens is or is not poised to help document introductions and 89 shifting distributions.

\section{Materials \& Methods}

\section{Biological data}

92

93

94

95

96

97

98

99

100

101

102

103

104

105

106

107

108

109

110

111

112

113

114

115

116

117

During the Ant Hunt, families and schools across Denmark collected ants by conducting baiting experiments at a site of their choosing. Participants ranged across all ages, but the average participants were children aged 5-11 years accompanied by a grown-up aged 31-50. They set out six different resources (saltwater, sugar water, oil, dissolved protein powder, a cookie and water) on bait cards and waited for two hours before collecting all the ants that were foraging on the cards. Ants were then frozen and counted before they were placed in $96 \%$ ethanol and sent to the Natural History Museum of Denmark for identification. All experiments were registered in an online database with date and GPS-coordinates (see supplemental material S1 for detailed protocol). In total, families and schools completed 792 experiments, of which 566 contained ants.

The ants were identified using a variety of taxonomic keys (Collingwood, 1979; Seifert, 2007; Douwes et al., 2012; Lebas et al., 2016; Wagner et al., 2017). In total, participants had collected 16,985 specimens from 29 species (Table 1). Of these, specimens from two experiments could not be identified to species level due to missing body parts and specimens from two experiments were flagged as potentially new taxa for Denmark. These were $T$. immigrans and Technomyrmex albipes. The establishment of Technomyrmex albipes could not be confirmed. However, after the original discovery of T. immigrans during the Ant Hunt, trained scientists resurveyed the location several times throughout 2015-2019. The presences of T. immigrans was confirmed during every survey and the species was seen to expand to an area of approx. 40 metres, with more than 20 nest entrances along the pavement.

Tetramorium immigrans (Fig. 1a and Fig. 1b) tends to have a larger overall body size, denser striation/sculpturation of the head, thorax and petiolar nodes, as well as a more pronounced microscopic scale pattern on the first gastral tergite than T. caespitum (Wagner et al., 2017). Because of the difficulty in distinguishing $T$. immigrans from other species in the $T$. caespitum complex, we visually inspected all specimens found of $T$. caespitum in the Ant Hunt and randomly selected 10 samples from a broad range of localities (Fig. 1c). These were then 
118 compared to the sixty-seven specimens of Tetramorium workers from the Botanical garden of

119 Copenhagen (Fig. 1d), which were examined visually for morphological characters

120 distinguishing typical forms of T. immigrans and T. caespitum. Voucher specimens were stored

121 at the Natural History Museum of Denmark (NHMD 0000188537).

122 One specimen was chosen to be inspected by X-ray micro computed tomography

123 (MicroCT). The specimen was placed on a designed holder and placed inside a Zeiss Xradia 410

124 versa system. The system was operated with a high voltage of $40 \mathrm{kV}$ and a power of $10 \mathrm{~W}$. The

125 data acquisition consisted of 3201 images while rotating 360 degrees, each image had a pixel

126 size of $4.14 \mu \mathrm{m}$. All data was reconstructed into a $4 \mathrm{~mm}$ by $4 \mathrm{~mm}$ by $4 \mathrm{~mm} 3 \mathrm{D}$ volume with a voxel

127 size of $4.14 \mu \mathrm{m}$. The reconstructed image is shown in figure $1 \mathrm{~b}$ and raw data is available through

128 Figshare (Gundlach, 2019).

\section{DNA analysis}

130 For the DNA analysis of T. immigrans we selected two specimens from the confirmed find in the 131 Botanical Gardens of Copenhagen, one from 2015 and one from 2018 and further selected 14

132 specimens of presumed T. caespitum, of which 10 had known coordinates and the remaining four 133 were known to be from somewhere in Denmark.

134 Up until DNA extraction, all samples from the Ant Hunt were kept in $96 \%$ ethanol in a 135 freezer, while samples from the Natural History Museum of Denmark had been kept as pinned 136 specimens. We extracted DNA by cutting off a small piece of the middle leg of each specimen, 137 to which we added $100 \mu 1$ of $10 \%$ Chelex in Tris solution. This was mixed and centrifuged for 13810 minutes, after which the solution was heated to $99^{\circ} \mathrm{C}$ for 15 minutes and centrifuged again. 139 The supernatant was used as a template for PCR reactions. We used primers LCO1490 and 140 HCO2198 (Folmer et al., 1994) to amplify mitochondrial COI gene and primer D2B and D3A-r 141 (Saux et al., 2004) to amplify nuclear 28S rDNA gene. PCR reactions were carried out using 142 REDTaq ReadyMix PCR Reaction Mix with $10 \mu \mathrm{g} / \mathrm{mL}$ Bovine serum albumin. The PCR 143 reaction conditions consisted of an initial denaturing step of $94^{\circ} \mathrm{C}$ for 5 minutes, followed by 35 144 cycles of $94^{\circ} \mathrm{C}$ for 40 seconds, $48^{\circ} \mathrm{C}$ (LCO1490/HCO2198) or $56^{\circ} \mathrm{C}(\mathrm{D} 2 \mathrm{~B} / \mathrm{D} 3 \mathrm{~A}-\mathrm{r})$ for 40 145 seconds, and $72^{\circ} \mathrm{C}$ for 60 seconds, and finally an extension step at $72^{\circ} \mathrm{C}$ for 5 minutes. PCR 146 products were purified using Invitek PCR clean-up MSB spin PCRapace kit and Sanger sequenced in both directions using the Mix2Seq from Eurofins.

Molecular identification was carried out by comparing samples to reference sequences from Wagner et al. 2017 (COI) and Schär et al. 2018 (28S). Raw sequences were edited and aligned using the software geneious v. 2019.0.4. A maximum likelihood tree with the best-fit model automatically selected by modelfinder and 1,000 rapid bootstrap replications was created for the alignment of COI sequences, using the program "IQ-TREE" v. 1.6.1 (Nguyen et al., 2015)).

Tetramorium immigrans has previously been found to be distinguished from similar species (including $T$. caespitum) by having a one base insertion (C) at site 438 of the $28 \mathrm{~S}$ rDNA fragment amplified by the primers D2B and D3A-r (Saux et al., 2004; Schär et al., 2018). We 
157 aligned the sequence of the specimen from Copenhagen to the reference sequences mentioned above to see if the characteristic insertion of $T$. immigrans is present.

159

160

161

162

163

164

165

166

167

168

169

170

171

172

173

174

175

176

177

178

179

180

181

182

183

184

185

186

187

188

189

190

191

192

193

194

195

All genetic data referred to in this publication are available via the European Nucleotide Archive project "PRJEB36036" (https://www.ebi.ac.uk/ena/browser/view/PRJEB36036).

\section{Climatic niches of $T$. immigrans and $T$. caespitum}

We compared the environmental niche and predicted geographical suitability based on climate of T. immigrans and T. caespitum in Europe using occurrence data from AntMaps (Guénard et al., 2017) and the Ant Hunt along with 10 climatic variables from Worldclim 1.4 at 2.5 arc-minutes ( $.5 \mathrm{~km}$ ) resolution (Hijmans et al., 2005).

Due to the recent distinction between T. caespitum and T. immigrans (Schlick-Steiner et al., 2006; Wagner et al., 2017), we used data points from 2006 onwards from trusted AntMaps sources (Borowiec \& Salata, 2018b; Espadaler et al., 2018, Schär et al., 2018; Wagner et al., 2018; Wagner et al., 2017). This resulted in 739 samples of $T$. caespitum and 187 samples of $T$. immigrans. Since T. immigrans was detected in only one location in Denmark, this one location does not contribute much to the overall niche analysis for the species.

We selected the climatic variables mean annual temperature, annual temperature seasonality, mean temperature of warmest quarter, mean temperature of coldest quarter, mean annual precipitation, annual precipitation seasonality, precipitation of wettest quarter, precipitation of driest quarter, precipitation of warmest quarter and precipitation of coldest quarter because these have been suggested to be the most relevant to T. immigrans (SchlickSteiner et al., 2006; Steiner et al., 2008). We then tested for autocorrelation between the 10 climatic variables through a correlation matrix (Fig. S1) using the R packages "Hmisc" (Harrell et al., 2019) and "PerformanceAnalytics" (Peterson \& Carl, 2019). There was a strong correlation between mean annual temperature and mean temperature of warmest quarter $(\mathrm{r}=$ $0.90, p<0.001)$ and mean temperature of coldest quarter $(r=0.94, p<0.001)$. Annual precipitation was strongly correlated with precipitation of wettest quarter $(\mathrm{r}=0.95)$ and precipitation of driest quarter $(\mathrm{r}=0.86, \mathrm{p}<0.001)$. Precipitation of warmest quarter and precipitation of coldest quarter were also strongly correlated $(r=1, p<0.001)$. We therefore discarded mean temperature of warmest quarter, mean temperature of coldest quarter, precipitation of wettest quarter, precipitation of driest quarter and precipitation of coldest quarter from the analysis, and kept the remaining five variables.

Using the ecospat package (Broennimann et al., 2018) in R (R Core Team, 2018), we compared the environmental niches of T. caespitum and T. immigrans in a gridded environmental space, where each cell corresponds to a unique set of the five climatic variables. We first calculated the density of occurrences and the climatic variables along two climatic axes of a multivariate analysis and then measured the niche overlap along the gradients of this multivariate analysis (as in Broennimann et al., 2012). Niche overlap was calculated using Schoener's overlap metric "D" (Schoener, 1968, 1970), which in this case compares the frequency of observations for each species within the chosen climatic categories (Schoener, 
196

197

198

199

200

201

202

203

204

205

206

207

208

209

210

211

212

213

214

215

216

217

218

219

220

221

222

223

224

225

226

227

228

229

230

231

232

1968). However, we acknowledge that there are other ways to measure niche overlap (see for example Seifert, 2017).

To test for niche equivalency and niche similarity, we compared the observed D metric with 1000 simulated values of $\mathrm{D}$. The niche equivalency test determines whether the overlap between the niches of the two species is higher than two random niches drawn from the same data pool. The niche similarity test determines whether the overlap between the two niches is higher than when one species' niche is randomly drawn in the study area (Broennimann et al., 2012). If the observed value of $D$ falls within the density of $95 \%$ of the simulated values, there is no detectable difference in the climatic niche of $T$. immigrans and $T$. caespitum. Finally, we projected the environmental niche of T. immigrans and T. caespitum onto Europe to visually compared the two species and pinpoint areas of suitable climate for T. immigrans to establish.

\section{Habitat differences}

We used the CORINE 100x100 m land cover raster dataset (Copernicus, 2012) and extracted land cover values for all data points for both species using the spatial analysis tool 'extract values to points' in ArcGIS (ESRI, 2010). The CORINE land cover dataset consists of 48 land cover types. For this analysis we excluded all data points that were labelled with no data or one of the water based land cover types ("water bodies", "water courses", "sea and ocean"). The remaining 39 land cover types were reduced to six major classes ("Artificial surface", "Agriculture", "Forest", "Scrub and/or herbaceous vegetation associations", "Open spaces with little or no vegetation" and "Wetlands") following the CORINE land cover nomenclature (Copernicus, 2015).

To test whether sampling of T. immigrans and T. caespitum were spatially biased, we compared the fraction of samples within each of the six land cover classes with the fraction of these land cover types in Europe using chi-square tests. We then did the same comparing the two species to each other to determine if T. immigrans and T. caespitum were being sampled in different habitats.

\section{Monitoring for new species}

In order to determine the suitability of citizen science for early detection and monitoring of introduced species, we compared the citizen scientist collected dataset of the Ant Hunt with a dataset collated from the Natural History Museum of Denmark, a personal collection by Sämi Schär and the Ph.D. course EuroAnts, which was collected in Denmark from 1990-2015, with 2015 being the most recent year with available data. We compared the datasets based on two measures, 1) distance to likely introduction sites and 2) sampling effort in different land cover types. We calculated the average distance from data points in each dataset to Denmark's seven major cities (cities of 50.000+ inhabitants) and 31 major harbours (harbours with a yearly goods turnover of one million ton) in ArcGIS (ESRI, 2010) and compared the two datasets using a Mann Whitney U-test. 
233

234

235

236

237

238

239

240

241

242

243

244

245

246

247

248

249

250

251

252

253

254

255

256

257

258

259

260

261

262

263

264

265

266

267

For the land cover analysis, we used the above-mentioned major categories, but also included the category Water as an approximation of samples collected close to the shore of water bodies (Copernicus, 2015). We summarised the number of samples collected in these seven major land cover classes and compared the observed values with expected values based on the availability of each land cover class using Chi-square tests. Based on availability of each land cover class we calculated the ratio of observed samples to expected samples to determine how much more or less a specific land cover type was sampled than what would be expected by chance.

\section{Results}

\section{Tetramorium immigrans}

Tetramorium immigrans was first discovered in the Botanical Garden of Copenhagen (55.69, 12.57) during a pilot run of the citizen science project in 2015 and was confirmed to be established and spreading in 2018 and 2019.

Although we did not collect traditional morphometric data, we regard the find of $T$. immigrans in Denmark to be verified. We base this determination on a maximum likelihood tree of the mitochondrial COI gene (Fig. 2a), the existence of a characteristic one base insertion (C) in the 28S rDNA fragment (Fig. 2b), and visual examination of diagnostic characters. This extends the northern limit of T. immigrans in Europe by three degrees latitude from Gmina Janowiec Wielkopolski, Poland (52.73, 17.50, Borowiec \& Salata, 2018a) to Copenhagen, Denmark $(55.69,12.57)$, almost $460 \mathrm{~km}$.

\section{Climatic niches of $T$. immigrans and $T$. caespitum}

Environmental niche overlap between T. immigrans and T. caespitum, measured as D, which compares the frequency of observations for each species within the chosen climatic categories, was $13 \%$ with only a slight difference of the niche centroid in environmental space (Fig. 3a). Based on the contribution of the five climatic variables along the two axes, $T$.

caespitum is present in colder and wetter areas, compared to T. immigrans, which prefers warmer and drier conditions with stable temperatures (Fig. 3b). Tetramorium immigrans and $T$. caespitum differed in mean climatic values for eight of the original ten climatic variables (Table S1 and Fig. S2), with no difference in precipitation seasonality and precipitation of coldest quarter. Despite these slight differences, the two species' niches were more similar to each other than two randomly drawn niches within the same data pool (niche equivalency test, $p=1$ ) and more similar than when a random niche of either species was drawn within the available climatic space (niche similarity test, $\mathrm{p}=0.22$ ).

Projection of the climatic niche into geographical space shows Eastern and Central Europe to be the most climatically suitable for both species along with the northern part of 
268 Southern Europe and the southern part of Northern Europe (Fig. 3cd), although T. immigrans 269 may have a slightly more southern distribution than T. caespitum.

\section{Habitat differences}

271 The current available data does not allow for an exact determination of the land use of $T$.

272 caespitum and $T$. immigrans, but we can determine in which land cover types the two species are 273 currently observed. Tetramorium caespitum was mostly observed in forest and agricultural land 274 use types (34.1\% and $34.96 \%$ of observations, respectively, Table 2 ). Tetramorium immigrans 275 was mostly found in land types with artificial surfaces (48.89\%, Table 2). Both species were 276 rarely found in wetland areas (T. immigrans: $1.11 \%$ and $T$. caespitum $0.14 \%$ of observations). 277 Observations of both species differed significantly from what would be expected if land use 278 reflected availability of the six land cover types in Europe (Chi square tests, $\chi^{2}=322.71$, $\mathrm{df}=5$, $279 \mathrm{p}<0.001$ for $T$. immigrans and $\chi^{2}=243.95, \mathrm{df}=5, \mathrm{p}<0.001$ for $T$. caespitum).

280 The two species also showed significant difference in the number of observations in each 281 land cover type compared to each other (Chi-square test, $\chi^{2}=82.66, \mathrm{df}=5, \mathrm{p}<0.001$ ).

282 Tetramorium immigrans was found almost three times more often in land use types with artificial 283 surfaces than T. caespitum (ratio: 0.35; Table 2). On the other hand, T. caespitum was sampled 284 over twice as often in forests than T. immigrans (ratio 2.56; Table 2).

285

286

287

288

289

290

291

292

293

294

295

296

297

298

299

300

301

\section{Monitoring for new species}

Overall, data collected by citizen scientists during the Ant Hunt was significantly closer to cities than data collected by scientists from 1990-2019 (mean $31.27 \mathrm{~km} \pm 29.72 \mathrm{SD}$ and $34.52 \mathrm{~km} \pm$ 23.21 SD, respectively, $\mathrm{W}=127623, \mathrm{p}<0.001)$. For the Ant Hunt, 101 of 667 observations $(15$ $\%)$ were within Denmark's major cities compared to only 4 out of 448 (0.9\%) scientist-collected samples. Data from the Ant Hunt was also significantly closer to major harbours than data from scientists (20.66 km $\pm 14.90 \mathrm{SD}$ and $28.25 \mathrm{~km} \pm 12.62 \mathrm{SD}$, respectively, $\mathrm{W}=98154, \mathrm{p}<0.001)$. Only six of the major harbours in Denmark were outside of cities with more than 5000 residents (Fig. 4), suggesting a high correlation between industrial harbours and residential areas.

Both scientists and citizen scientists were significantly biased regarding which land cover classes they sampled within (Chi-square test, $\chi^{2}=653.75$, $\mathrm{df}=6, \mathrm{p}<0.001$ and $\chi^{2}=$ 3094.4, df $=6, p<0.001$, respectively). However, although both datasets were biased towards areas with artificial surfaces, the effect was far more pronounced among citizen scientists, who sampled artificially surfaced areas eight times more than expected. Scientists only sampled artificial surface areas three times more than expected by random sampling. Both citizens and scientists avoided agricultural areas, but scientists sampled forests, scrub, coastal areas and wetlands 2-3 times more than expected by random sampling (Table 3). 


\section{Discussion}

303 Genetic comparison of the Danish Tetramorium immigrans samples with samples from Wagner

304

305

306

307

308

309

310

311

312

313

314

315

316

317

318

319

320

321

322

323

324

325

326

327

328

329

330

331

332

333

334

335

336

337

338

339 et al. 2017 (COI) and Schär et al. 2018 (28S) confirmed that T. immigrans is established in Denmark. However, genetic analysis of 14 additional Tetramorium samples from Denmark collected during the Ant Hunt in 2017 and 2018 conclude that, so far, the distribution of $T$. immigrans in Denmark is limited to the Botanical Garden of Copenhagen.

The climatic niche of the two species overlapped by $13 \%$ and our study confirms previous assessments that T. immigrans prefers warmer and drier climates than T. caespitum (Seifert, 2018). Mean temperature of warmest quarter $\left({ }^{\circ} \mathrm{C}\right)$ was $20.27 \pm 2.06 \mathrm{SD}$ for $T$. immigrans and $16.77 \pm 2.43 \mathrm{SD}$ for $T$. caespitum. This is in accordance with previously recorded standard air temperatures $\left({ }^{\circ} \mathrm{C}\right)$ for May-August for both species $(19.9 \pm 2.5$ and 16.1 $\pm 2.0 \mathrm{SD}$, respectively; Wagner et al., 2017).

There was a large discrepancy between identified climatically suitable areas based on the climatic niche model and current known distribution of T. immigrans, in accordance with previous models of the climatic niche for T. immigrans (Steiner et al., 2008). Coupled with the knowledge that northern observations of T. immigrans have been largely within cities and the large gap in the known distribution from Poland to Denmark, we deem it likely that T. immigrans is not native to northern Europe and is being accidentally introduced by humans.

Others have also hypothesized that T. immigrans may not be native in most of Europe. Specifically, the species is thought to be introduced in France, Germany and Poland (Gippet et al., 2017; Borowiec \& Salata, 2018a; Seifert, 2018; Cordonnier et al., 2019). If true, its' current observed distributional focus in Southern Europe, along with the highest COI variability being in Anatolia and the Caucausus region (Wagner et al., 2017) could be an indication of its' origin.

Whether T. immigrans will be able to further establish and spread in Central, Northeastern and Northern Europe will depend on a number of factors common for establishment success, including propagule pressure (Lockwood et al., 2005) and competition with pre-established species (Menke et al., 2007). It may well be, that $T$. immigrans will not be able to spread beyond cities in its' northern range, which is a common pattern for introduced species (King \& Porter, 2007). Certainly, places identified as climatically suitable by the species distribution model should be monitored closely (Fig. 3d) and further studies on the species' distribution, competitive ability and climatic tolerances would be of high value to determine the risk of spread.

While not a main goal of the Ant Hunt, the finding of this species shows how the engagement of untrained volunteers, even children, can be a great asset to the monitoring of biodiversity, especially when it comes to detecting newly introduced species. This is evident from the sample bias of citizen scientists towards cities, harbours and areas of high human disturbance. On the other hand, scientists are more prone to sampling in natural areas. We argue the case that engaging the aid of amateur participants; even as young as 6-10 year-old children, 
340 can be a valuable tool for biodiversity monitoring. Citizen scientists are best able to search for 341 species where scientists are most likely to miss them and where introductions are most likely.

\section{Conclusions}

343 We hypothesized that, although not necessarily the main goal of citizen science projects, these 344 projects have a high likelihood of turning up new species, due to the large amount of sampling 345 being carried out in areas of likely introduction, such as harbours and cities.

346 During the Ant Hunt, a citizen science project, where children set out baiting experiments

347 to help understand the community composition and resource requirements of ants under different

348 environmental conditions, two new species were discovered. One species, Tetramorium

349 immigrans, was determined to be established in the Botanical Garden of the Natural History

350 Museum of Denmark in Copenhagen.

351

Our findings push the distribution of $T$. immigrans north by almost $460 \mathrm{~km}$. Our

352 subsequent analysis of the climatic niche and potential geographical distribution of T. immigrans adds some support to the current speculation that this species may not be native to all of Europe and is spreading through introduction to cities, with many currently uninhabited locations identified as climatically suitable. A systematic survey of the land use preferences of $T$. immigrans along with a genetic mapping is needed to fully map and understand the dispersal of T. immigrans across Europe.

\section{8}

359

360

361

362

363

364

365

366

367

368

369

370

371

\section{Acknowledgements}

We would like to thank all the children and citizen scientists who helped collect the data for the Ant Hunt. A special thanks to the children at Sølvgade School, who first discovered $T$. immigrans in Denmark.

\section{References}

Bellard, C., Thuiller, W., Leroy, B., Genovesi, P., Bakkenes, M. \& Courchamp, F. (2013) 'Will climate change promote future invasions?', Global Change Biology, 19: 3740-3748. doi: $10.1111 / \mathrm{gcb} .12344$.

Borowiec, L. \& Salata, S. (2018a) 'Tetramorium immigrans Santschi, 1927 (Hymenoptera: Formicidae) nowy gatunek potencjalnie inwazyjnej mrówki w Polsce', Acta entomologica silesiana 26: 1-5. doi: 10.5281/zenodo.1169156.

Borowiec L. \& Salata, S. (2018b) 'Notes on ants (Hymenoptera: Formicidae) of the Euboea Island, Central Greece', Annals of the Upper Silesian Museum in Bytom Entomology 27(5): 115. 
372 Broennimann, O., Fitzpatrick, M. C., Pearman, P. B., Petitpierre, B., Pellissier, L., Yoccoz, N. 373 G., Thuiller, W., Fortin, M.-J., Randin, C., Zimmermann, N. E., Graham, C. H. \& Guisan, A.

374 (2012) 'Measuring ecological niche overlap from occurrence and spatial environmental data',

375 Global Ecology and Biogeography, 21(4): 481-497. doi: 10.1111/j.1466-8238.2011.00698.x.

376 Broennimann, O., Cola, V. Di \& Guisan, A. (2018) 'ecospat: Spatial Ecology Miscellaneous

377 Methods. R package version 3.0.’ Available at: https://cran.r-project.org/package=ecospat.

378 Collingwood, C. A. (1979) The Formicidae (Hymenoptera) of Fennoscandia and Denmark, 379 Fauna Entomolgica Scandinavica.

380 Copernicus (2012) 'Corine Land Cover 100m'. European Union, Copernicus Land Monitoring 381 Service.

382 Copernicus (2015) CORINE Land Cover nomenclature conversion to Land Cover Classification 383 system. Available at: https://land.copernicus.eu/eagle/files/eagle-related-projects/pt_clc-

384 conversion-to-fao-lccs3_dec2010.

385 Cordonnier, M., Gayet, T., Escarguel, G. \& Kaufmann, B. (2019) 'From hybridization to 386 introgression between two closely related sympatric ant species', Journal of Zoological 387 Systematics and Evolutionary Research: 1-11. doi: 10.1111/jzs.12297.

388 Danske Havne (2017) Danish Harbours. Available at: http://www.danskehavne.dk/ (Accessed: 38919 January 2017).

390 Douwes, P., Abenius, J., Cederberg, B., Wahlstedt, U., Hall, K., Starkenberg, M., Reisborg, C. \& 391 Östman, T. (2012) Nationalnyckeln till Sveriges flora och fauna. Steklar: Myror - getingar.

392 Hymenoptera: Formicidae-Vespidae. Uppsala: ArtDatabanken, SLU.

393 Espadaler X., Pradera, C. \& Santana, J.A. (2018) 'The first outdoor-nesting population of 394 Wasmannia auropunctata in continental Europe (Hymenoptera, Formicidae)', Iberomyrmex 10: 395 1-8.

396 ESRI (2010) ‘ArcGIS’. Environmental Systems Research Institute.

397 Folmer, O., Black, M., Hoeh, W., Lutz, R. \& Vrijenhoek, R. (1994) 'DNA primers for 398 amplification of mitochondrial cytochrome c oxidase subunit I from diverse metazoan 399 invertebrates', Molecular marine biology and biotechnology, 3(5): 294-299.

400 Gippet, J. M. W., Mondy, N., Diallo-Dudek, J., Bellec, A., Dumet, A., Mistler, L. \& Kaufmann, 401 B. (2017) 'I'm not like everybody else: urbanization factors shaping spatial distribution of native 402 and invasive ants are species-specific', Urban Ecosystems, 20, pp. 157-169. doi:

403 10.1007/s11252-016-0576-7. 
404 Guénard, B., Weiser, M. D., Gómez, K., Narula, N. \& Economo, E. P. (2017) 'The Global Ant 405 Biodiversity Informatics (GABI) database: Synthesizing data on the geographic distribution of 406 ant species (Hymenoptera: Formicidae)', Myrmecological News, 24: 83-89.

407 Gundlach, C. (2019) Tetramorium immigrans visualisation files. figshare. Media.

408 Harrell F. E. Jr, Dupont, C. et al. (2019). Hmisc: Harrell Miscellaneous. R package version 4.3-0. 409 https://CRAN.R-project.org/package=Hmisc

410 Hijmans, R. J., Cameron, S. E., Parra, J. L., Jones, P. G. \& Jarvis, A. (2005) 'Very high 411 resolution interpolated climate surfaces for global land areas', International Journal of 412 Climatology, 25(15): 1965-1978. doi: 10.1002/joc.1276.

413 Holway, D. A., Lach, L., Suarez, A. V., Tsutsui, N. D. \& Case, T. J. (2002) 'The causes and 414 consequences of ant invasions', Annual Review of Ecology and Systematics, 33: 181-233. doi: 415 10.1146/annurev.ecolsys.33.010802.150444.

416 IPBES (2019) Global assessment report on biodiversity and ecosystem services of the 417 Intergovernmental Science-Policy Platform on Biodiversity and Ecosystem Services. Edited by 418 S. Díaz, J. Settele, E. S. Brondízio E.S., H. T. Ngo, M. Guèze, J. Agard, A. Arneth, P. Balvanera, 419 K. A. Brauman, S. H. M. Butchart, K. M. A. Chan, L. A. Garibaldi, K. Ichii, J. Liu, S. M. 420 Subramanian, G. F. Midgley, P. Miloslavich, Z. Molnár, D. Obura, A. Pfaff, S. Polasky, A. 421 Purvis, J. Razzaque, B. Reyers, R. Roy Chowdhury, Y. J. Shin, I. J. Visseren-Hamakers, K. J. 422 Willis, and C. N. Zayas. IPBES secretariat, Bonn, Germany. 56 pages.

423 King, J. R. \& Porter, S. D. (2007) 'Body size, colony size, abundance, and ecological impact of 424 exotic ants in Florida’s upland ecosystems’, Evolutionary Ecology Research, 9: 757-774.

425 Lebas, C., Galkowski, C., Blatrix, R. \& Wegnez, P. (2016) Fourmis d'Europe occidentale. Paris: 426 delachaux et niestlé.

427 von der Lippe, M. \& Kowarik, I. (2007) 'Long-distance dispersal of plants by vehicles as a 428 driver of plant invasions.', Conservation biology, 21(4): 986-96. doi: 10.1111/j.1523429 1739.2007.00722.x.

430 Lessard, J.-P. \& Buddle, C. M. (2005) 'The effects of urbanization on ant assemblages 431 (Hymenoptera: Formicidae) associated with the Molson Nature Reserve, Quebec', The Canadian 432 Entomologist, 137(02): 215-225. doi: 10.4039/n04-055.

433 Lockwood, J., Cassey, P. \& Blackburn, T. (2005), 'The role of propagule pressure in explaining 434 species invasions', Trends in Ecology and Evolution, 20(5): 223-228. 
435 Lowe, S., Browne, M., Boudjelas, S. \& De Poorter, M. (2000) '100 of the world's worst invasive 436 alien species. A selection from the Global Invasive Species Database', The Invasive Species 437 Specialist Group (ISSG) a specialist group of the Species Survival Commission (SSC) of the 438 World Conservation Union (IUCN), p. 12. doi: 10.1614/WT-04-126.1.

439 Menke, S. B., Fisher, R. N., Jetz, W. \& Holway, D. A. (2007) 'Biotic and abiotic controls of 440 Argentine ant invasion success at local and landscape scales’, Ecology, 88: 3164-3173.

441 Meurisse, N., Rassati, D., Hurley, B. P., Brockerhoff, E. G. \& Haack, R. A. (2019) 'Common 442 pathways by which non-native forest insects move internationally and domestically', Journal of 443 Pest Science, 92(1): 13-27. doi: 10.1007/s10340-018-0990-0.

444 Nguyen, L. T., Schmidt, H. A., Von Haeseler, A. \& Minh, B. Q. (2015) 'IQ-TREE: A fast and 445 effective stochastic algorithm for estimating maximum-likelihood phylogenies', Molecular 446 Biology and Evolution, 32(1): 268-274. doi: 10.1093/molbev/msu300.

447 O’Connor, S. \& Weston, G. P. (2010) 'Box 13.1', in Lach, L., Parr, C. L. \& Abbott, K. L. (eds.) 448 Ant Ecology. New York: Oxford University Press, p. 242-243.

449 Oke, T. R. (1973) 'City size and the urban heat island', Atmospheric Environment Pergamon 450 Pres, 7: 769-779. doi: 10.1016/0004-6981(73)90140-6.

451 Peterson, B. G. \& Carl, P. (2019) PerformanceAnalytics: Econometric Tools for Performance 452 and Risk Analysis. R package version 1.5.3. https://CRAN.R-

453 project.org/package=PerformanceAnalytics

454 R Core Team (2018) 'R: A language and environment for statistical computing.' Vienna, 455 Austria: R Foundation for Statistical Computing. Available at: https://www.r-project.org/.

456 Sanders, N. J. \& Suarez, A. V. (2011) 'Elton's Insights into the Ecology of Ant Invasions: 457 Lessons Learned and Lessons Still to be Learned', in Richardson, D. M. (ed.) Fifty years of 458 invasion ecology - the legacy of Charles Elton. Wiley Blackwell, p. 239-251.

459 Sauer, J. R. Pardieck, K. L., Ziolkowski, D. J., Smith, A. C., Hudson, M.-A. R., Rodriguez, V., 460 Berlanga, H., Niven, D. K. \& Link, W. A. (2017) 'The first 50 years of the North American 461 Breeding Bird Survey', The Condor, 119(3): 576-593. doi: 10.1650/CONDOR-17-83.1.

462 Saux, C., Fisher, B. L. \& Spicer, G. S. (2004) 'Dracula ant phylogeny as inferred by nuclear 28 S 463 rDNA sequences and implications for ant systematics (Hymenoptera: Formicidae:

464 Amblyoponinae)', Molecular Phylogenetics and Evolution, 33(2): 457-468. doi:

465 10.1016/j.ympev.2004.06.017. 
466 Schär, S., Talavera, G., Espadaler, X., Rana, J. D., Andersen A. A., Cover, S. P. \& Vila, R. 467 (2018) 'Do Holarctic ant species exist? Trans-Beringian dispersal and homoplasy in the 468 Formicidae', Journal of Biogeography, 45(8): 1917-1928. doi: 10.1111/jbi.13380.

469 Schär, S., Illum, A. A. \& Larsen, R. S. (2017) 'Exotic ants in Denmark (Hymenoptera:

470 Formicidae)', Entomologiske Meddelelser, 85(1-2): 101-109.

471 Schlick-Steiner, B. C., Steiner, F. M., Moder, K., Seifert, B., Sanetra, M., Dyreson, E., Stauffer, 472 C. \& Christian, E. (2006) 'A multidisciplinary approach reveals cryptic diversity in Western 473 Palearctic Tetramorium ants (Hymenoptera: Formicidae)', Molecular Phylogenetics and 474 Evolution, 40(1): 259-273. doi: 10.1016/j.ympev.2006.03.005.

475 Schoener, T. W. (1968) 'The Anolis Lizards of Bimini: Resource Partitioning in a Complex 476 Fauna', Ecology, 49(4): 704-726.

477 Schoener, T. W. (1970) 'Nonsynchronous Spatial Overlap of Lizards in Patchy Habitats', 478 Ecology, 51(3): 408-418.

479 Seifert, B. (2007) Die Ameisen Mittel- und Nordeuropas. Lutra Verlags- und 480 Vertriebsgesellschaft, Tauer, $368 \mathrm{pp}$.

481 Seifert, B. (2017) 'The ecology of Central European non-arboreal ants -37 years of a broad482 spectrum analysis under permanent taxonomic control'. Soil Organisms, 89: 1-67.

483 Seifert, B. (2018) The Ants of Central and North Europe. Lutra Verlags- und 484 Vertriebsgesellschaft, Tauer, 408 pp.

485 Steiner, F. M., Schlick-Steiner, B. C., VanDerWal, J., Reuther, K. D., Christian, E., Stauffer, C., 486 Suarez, A. V., Williams, S. E. \& Crozier, R. H. (2008) 'Combined modelling of distribution and 487 niche in invasion biology: a case study of two invasive Tetramorium ant species', Diversity and 488 Distributions, 14(3): 538-545. doi: 10.1111/j.1472-4642.2008.00472.x.

489 Suarez, A., McGlynn, T. \& Tsutsui, N. (2010) 'Biogeographic and Taxonomic Patterns of 490 Introduced Ants', in Lach, L., Parr, C. L., and Abbott, K. L. (eds) Ant Ecology. New York: 491 Oxford University Press, p. 424.

492 Theobald, E. J., Ettinger, A. K., Burgess, H. K., DeBey, L. B., Schmidt, N. R., Froehlich, H. E., 493 Wagner, C., HilleRisLambers, J., Tewksbury, J., Harsch, M. A. \& Parrish, J. K. (2015) 'Global 494 change and local solutions: Tapping the unrealized potential of citizen science for biodiversity 495 research', Biological Conservation, 181: 236-244. doi: 10.1016/j.biocon.2014.10.021. 
496 Toennisson, T. A., Sanders, N. J. \& Klingeman, W. E. (2011) 'Influences on the Structure of 497 Suburban Ant (Hymenoptera: Formicidae) Communities and the Abundance of Tapinoma 498 sessile', Community and Ecosystem Ecology, 40(6), pp. 1397-1404.

499 Del Toro, I., Ribbons, R. R. \& Pelini, S. L. (2012) 'The little things that run the world revisited: 500 A review of ant-mediated ecosystem services and disservices (Hymenoptera: Formicidae)', 501 Myrmecological News, 17: 133-146.

502 Tulloch, A. I. T., Possingham, H. P., Joseph, L. N., Szabo, J. \& Martin, T. G. (2013) 'Realising 503 the full potential of citizen science monitoring programs', Biological Conservation. Elsevier Ltd, 504 165: 128-138. doi: 10.1016/j.biocon.2013.05.025.

505 Wagner, H. C., Arthofer, W., Seifert, B., Muster, C., Steiner, F.M. \& Schlick-Steiner, B.C. 506 (2017) 'Light at the end of the tunnel: Integrative taxonomy delimits cryptic species in the 507 Tetramorium caespitum complex (Hymenoptera: Formicidae)', Myrmecological News, 25: 95508129.

509 Wagner, H. C., Karaman, C., Aksoy, V. \& Kiran, K. (2018) 'A mixed colony of Tetramorium 510 immigrans Santschi, 1927 and the putative social parasite Tetramorium aspina sp.n.

511 (Hymenoptera: Formicidae)', Myrmecological News 28: 25-33. 


\section{Table $\mathbf{1}$ (on next page)}

List of the number of experiments each species was found in during the pilot study of the Ant Hunt in 2015 and the full study, which ran throughout April-September in 2017 and 2018.

${ }^{1}$ New taxa for Denmark. ${ }^{2}$ Individuals that were not determined to species level. An experiment consisted of a baiting trial, where salt, sugar, olive oil, protein powder, water and cookies were left out for two hours after which all ants that had recruited to the baits were collected. 


\begin{tabular}{|c|c|}
\hline Species & Experiments \\
\hline Formica cinerea & 11 \\
\hline Formica exsecta & 1 \\
\hline Formica fusca & 89 \\
\hline Formica lugubris & 1 \\
\hline Formica picea & 1 \\
\hline Formica polyctena & 43 \\
\hline Formica pratensis & 1 \\
\hline Formica pressilabris & 1 \\
\hline Formica rufa & 7 \\
\hline Formica rufibarbis & 6 \\
\hline Formica sanguinea & 2 \\
\hline${\text { Formica } \text { sp. }^{2}}^{2}$ & 1 \\
\hline Formica truncorum & 2 \\
\hline Hypoponera & \\
\hline punctatissima & 1 \\
\hline Lasius flavus & 23 \\
\hline Lasius fuliginosus & 12 \\
\hline Lasius niger & 354 \\
\hline Lasius platythorax & 47 \\
\hline Lasius psammophilus & 2 \\
\hline Lasius umbratus & 1 \\
\hline Myrmecinae sp. ${ }^{2}$ & 1 \\
\hline Myrmica lobicornis & 2 \\
\hline Myrmica rubra & 37 \\
\hline Myrmica ruginodis & 35 \\
\hline Myrmica rugulosa & 6 \\
\hline Myrmica sabuleti & 4 \\
\hline Myrmica scabrinodis & 4 \\
\hline Myrmica schencki & 3 \\
\hline Technomyrmex albipes ${ }^{1}$ & 1 \\
\hline Tetramorium caespitum & 26 \\
\hline Tetramorium immigrans 1 & 1 \\
\hline
\end{tabular}

1 


\section{Table 2 (on next page)}

Overview of the distribution of observation points for $T$. caespitum and $T$. immigrans across six broad land cover categories.

Land cover categories were derived from CORINE 2012 and their availability was summarized across Europe. The ratio of occurrences in each land cover type by the two species is calculated as T. caespitum:T. immigrans. Occurrence data was received from antmaps.org and combined with the samples from the Ant Hunt. 


\begin{tabular}{|c|c|c|c|c|c|c|}
\hline \multirow[t]{2}{*}{ Land cover class } & \multirow{2}{*}{$\begin{array}{r}\text { Europe } \\
\% \\
\end{array}$} & \multicolumn{2}{|c|}{ T. caespitum } & \multicolumn{2}{|c|}{ T. immigrans } & \multirow{2}{*}{$\begin{array}{r}\text { Species } \\
\text { ratio }\end{array}$} \\
\hline & & counts & $\%$ & counts & $\%$ & \\
\hline Artificial surfaces & 4.14 & 121 & 17.34 & 88 & 48.89 & 0.35 \\
\hline Agriculture & 43.03 & 244 & 34.96 & 47 & 26.11 & 1.34 \\
\hline Forest & 30.06 & 238 & 34.1 & 24 & 13.33 & 2.56 \\
\hline Scrub/herbaceous vegetation & 14.12 & 84 & 12.03 & 16 & 8.89 & 1.35 \\
\hline Open with little-no vegetation & 6.06 & 10 & 1.43 & 3 & 1.67 & 0.88 \\
\hline Wetlands & 2.61 & 1 & 0.14 & 2 & 1.11 & 0.13 \\
\hline Total & 100 & 698 & 100 & 180 & 100 & \\
\hline
\end{tabular}




\section{Table 3 (on next page)}

Sampling effort across land cover types.

Observed (Obs.) number of samples collected within each land cover type by scientists and citizen scientists (CS) and the expected (Exp.) value if samples had been collected in accordance to availability. The ratio column refers to the ratio of observed:expected number of samples, a value of 1 would mean that a land cover type is sampled equally to its availability. 


\begin{tabular}{lrrrrrrrrr}
\hline Land cover class & Denmark & & \multicolumn{3}{c}{ Scientists $(\mathrm{n}=448)$} & & \multicolumn{3}{c}{ CS (n=667) } \\
\cline { 2 - 3 } \cline { 9 - 10 } & Proportion & & Obs. & Exp. & Ratio & & Obs. & Exp. & Ratio \\
\hline Agriculture & 0.76 & & 112 & 338 & 0.33 & & 145 & 504 & 0.29 \\
Artificial surface & 0.08 & & 107 & 34 & 3.14 & & 429 & 51 & 8.46 \\
Forest & 0.09 & & 139 & 39 & 3.53 & & 54 & 59 & 0.92 \\
Open with little-no veg. & 0.00 & & 0 & 0 & 0.00 & & 1 & 1 & 1.50 \\
Scrub/herbaceous veg. & 0.04 & & 53 & 17 & 3.11 & & 30 & 25 & 1.18 \\
Waterside & 0.02 & & 21 & 10 & 2.13 & & 5 & 15 & 0.34 \\
Wetlands & 0.02 & & 16 & 9 & 1.79 & & 3 & 13 & 0.22 \\
\hline
\end{tabular}

1 


\section{Figure 1}

Tetramorium immigrans in Denmark.

a) Photo of $T$. immigrans specimen from the Botanical Garden of Copenhagen. Taken by Rasmus S. Larsen and edited to remove background. Scale: $1 \mathrm{~mm}$. b) CT-scan of $T$. immigrans by Carsten Gundlach, 3D Imaging Center, DTU. Scale $0.7 \mathrm{~mm}$. A video of the scan is available as Video S1. c) Map of Denmark showing analysed samples of $T$. caespitum (filled orange crosses, 10 localities), observed localities of $T$. caespitum (open orange crosses, 83 localities), the location of $T$. immigrans (blue star) and localities of Ant Hunt experiments where neither $T$. caespitum nor $T$. immigrans was found (open red circles, 735 experiments). d) Zoom in of the Botanical Garden at the Natural History Museum of Denmark in Copenhagen from Google Maps. Red circles indicate locations of T. immigrans. 

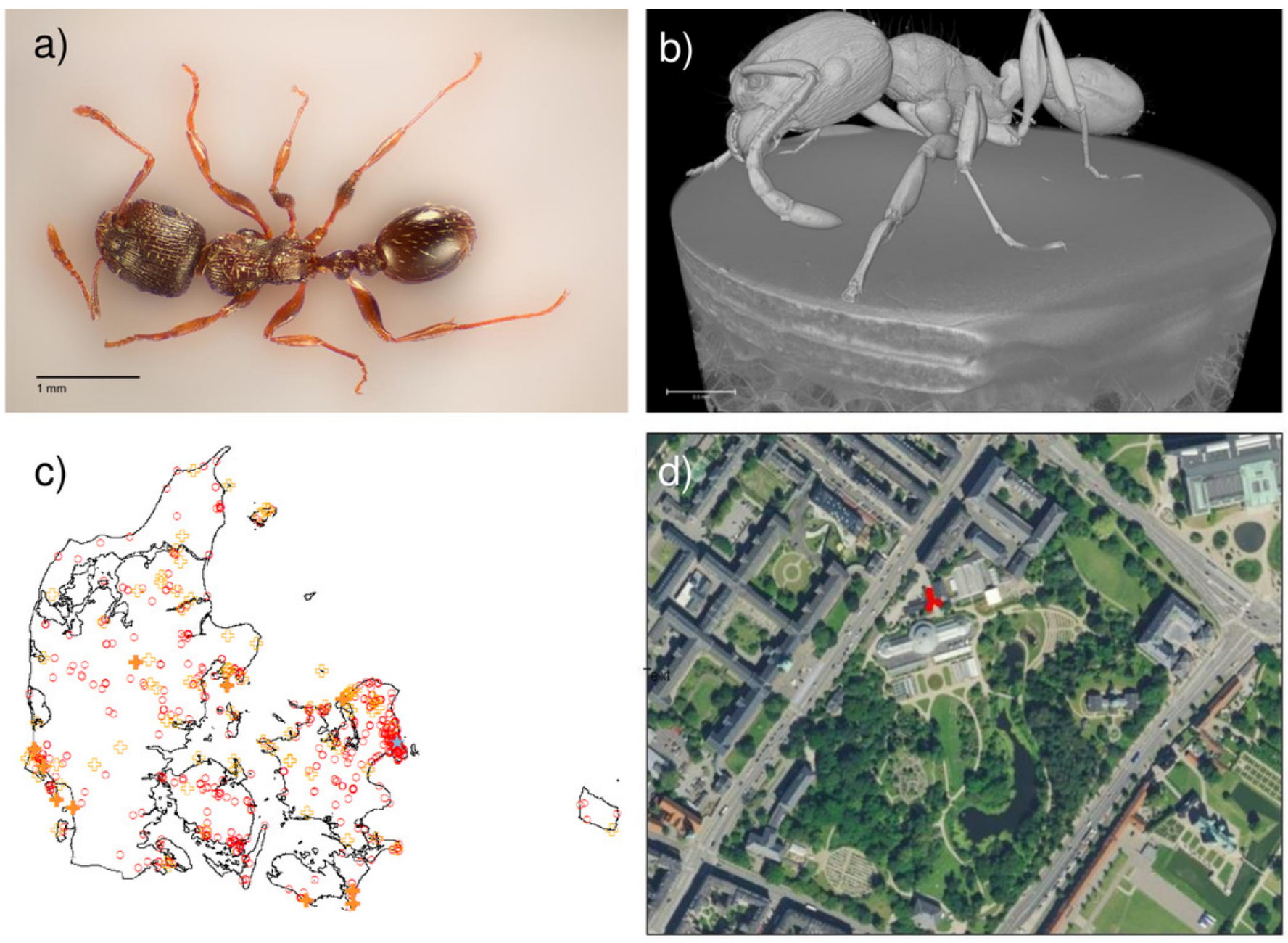


\section{Figure 2}

Molecular identification of $T$. immigrans from the Botanical Garden of Copenhagen.

a) A maximum likelihood tree for the mitochondrial $\mathrm{COI}$ gene. The reference alignment is the full alignment from Wagner et al. 2017 (757 sequences available from GenBank). The red arrow shows the position of the sequence from Copenhagen within mtDNA lineage $E$, predominantly consisting of $T$. immigrans. Other clades within the tree have been collapsed for simplicity. b) $28 \mathrm{~S}$ rDNA alignment (T. immigrans) showing a characteristic insertion of (C) at position 438 of the fragment amplified by the primers D2B and D3A-r, apparently not shared by T. caespitum and other members of the T. caespitum complex (Schär et al. 2018). The lowest sequence and chromatogram are from the sample from Copenhagen, showing the typical insertion (C) of $T$. immigrans at site 438 . 


\section{a) mIDNA (COI)}

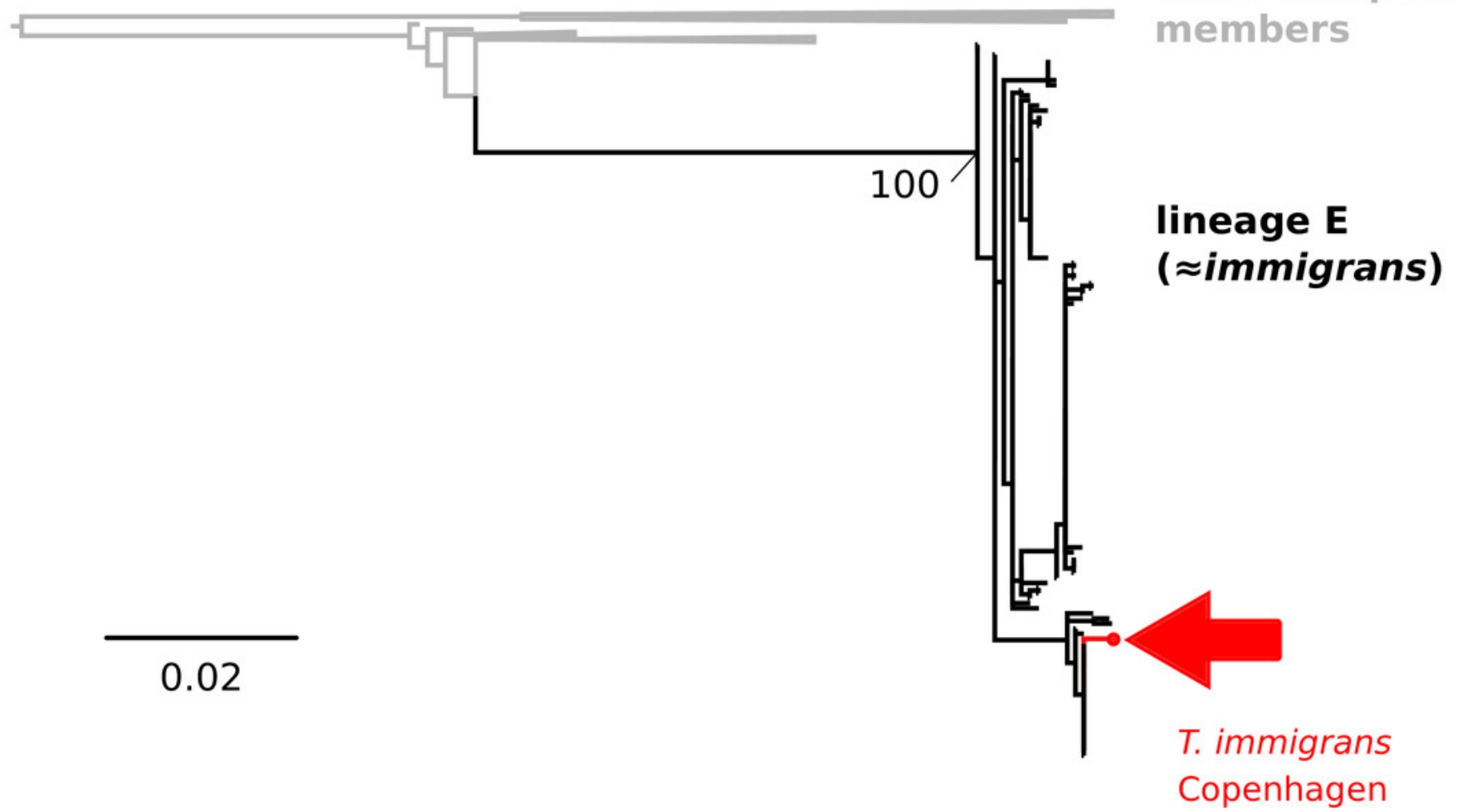

\section{b) nuclear DNA (28S)}

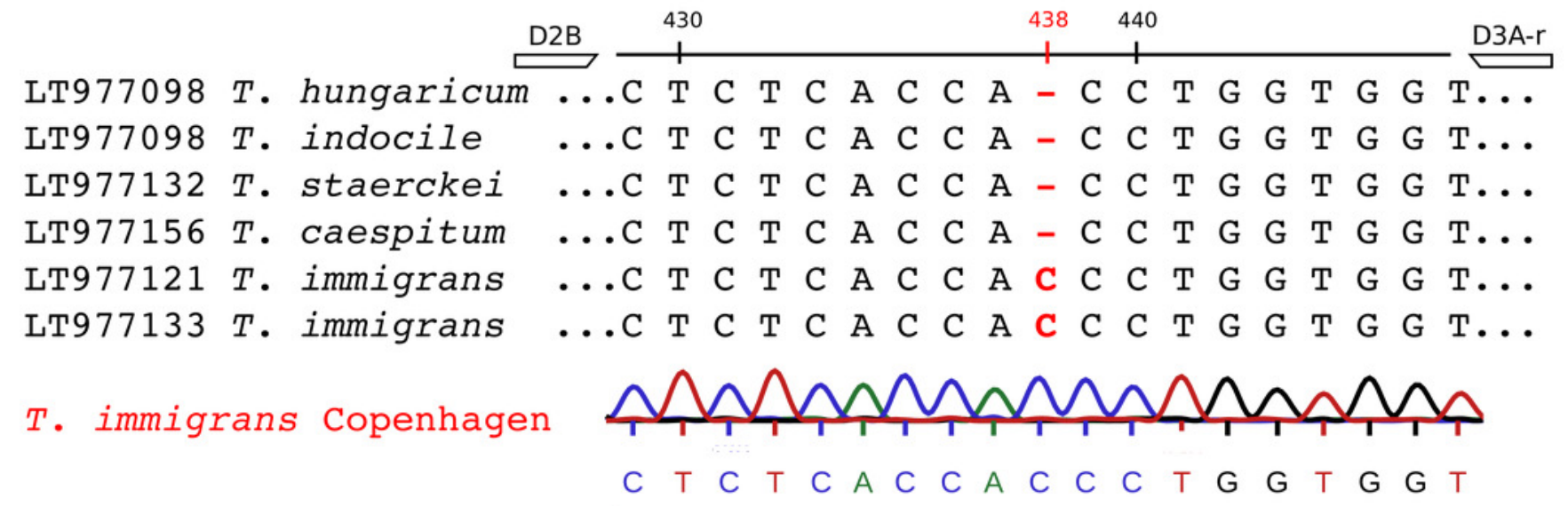




\section{Figure 3}

Climatic niche of Tetramorium caespitum and Tetramorium immigrans.

a) Climatic niche of $T$. caespitum (orange) and $T$. immigrans (blue) along the two first axes of the PCA analysis. Yellow indicates niche space occupied by both species. Black and dashed contour lines indicate $100 \%$ and $75 \%$ available European (background) climate. The arrow marks the difference between the niche centres of the two species. b) Correlation circle indicating the contribution of the ten climatic predictors to the PCA axes of Fig. 3a. The ten climatic variables have been grouped into categories indicating temperature, precipitation and seasonality changes along the two axes. c) Geographical model of climatic suitability of Europe for T. caespitum. Red dots are data points used in the analysis. Darker shading indicates higher suitability. d) Geographical model of climatic suitability of Europe for $T$. immigrans. Red dots are data points used in the analysis. Darker shading indicates higher suitability. 

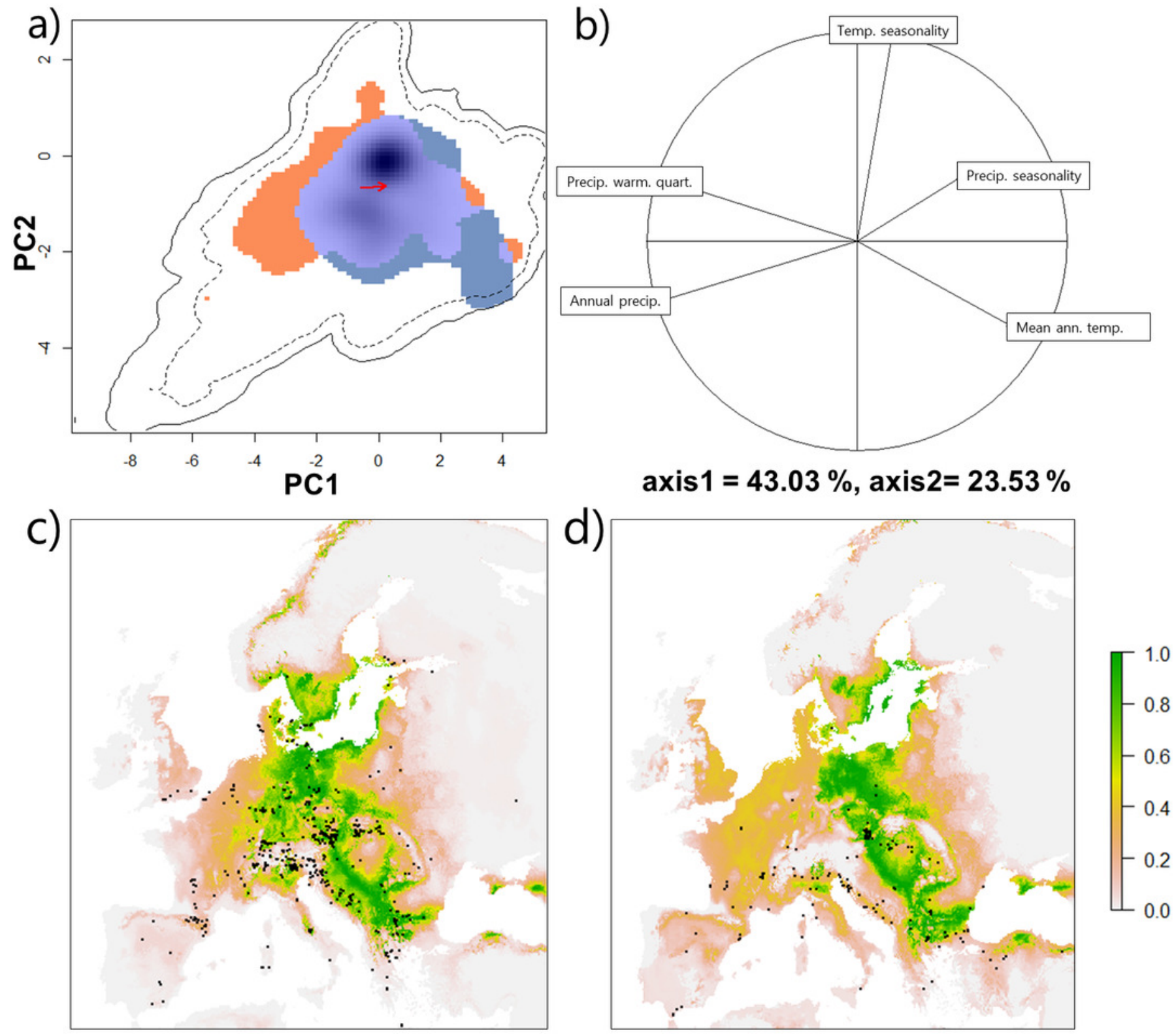


\section{Figure 4}

Distribution of observations by scientists and citizen scientists in Denmark.

Samples of ants in Denmark collected by scientists are in purple and samples collected by citizen scientists through the Ant Hunt are in yellow. The location of the major harbours are marked by blue triangles and cities with over 5000 residents are marked as red polygons. Six of the major cities used in this study are labelled by name. The seventh, Frederiksberg, is not, because it is a city within København (Copenhagen).

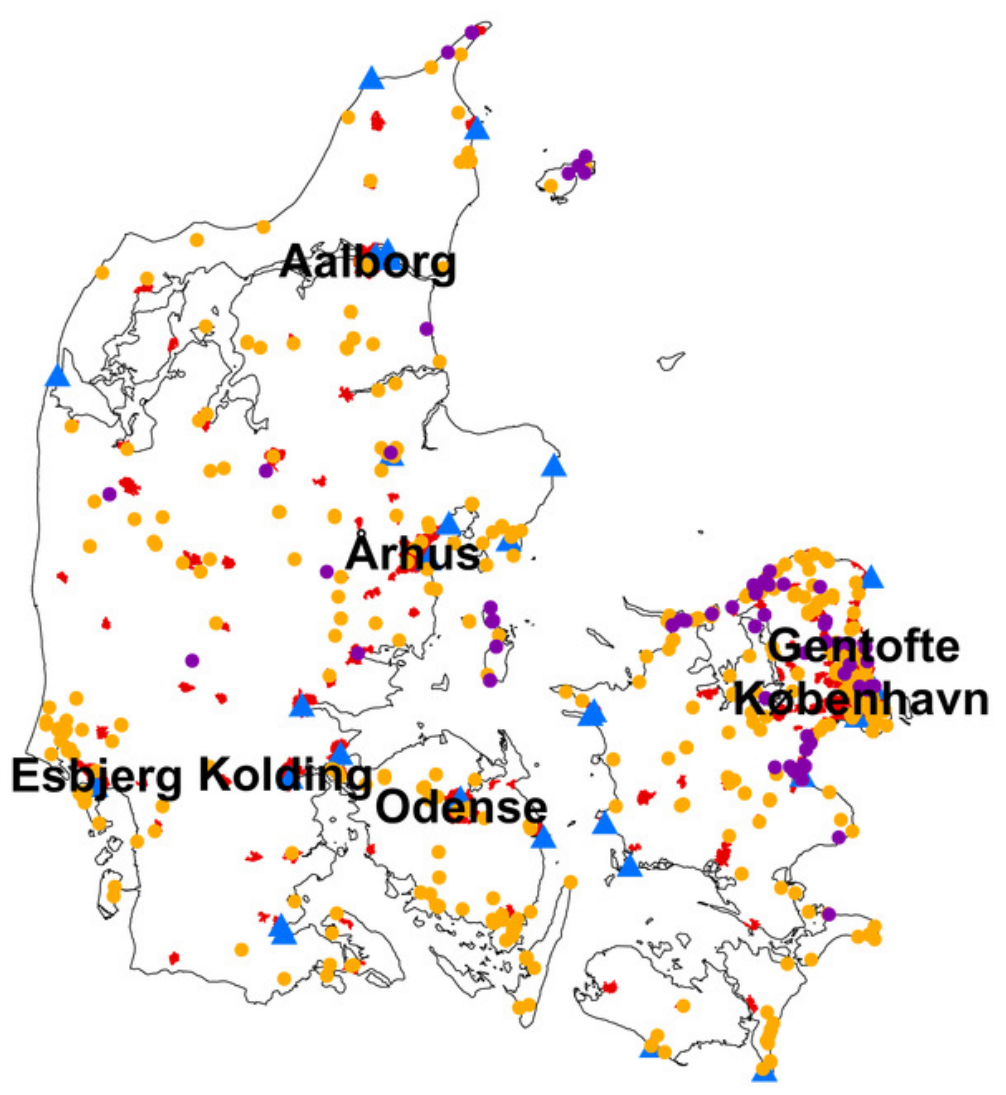

- Scientists - The Ant Hunt $\Delta$ Major harbours $\square$ Cities 